\title{
Chronic Stress, Acute Stress, and Depressive Symptoms ${ }^{1}$
}

\author{
Katherine A. McGonagle and Ronald C. Kessler ${ }^{2}$ \\ University of Michigan
}

Although life events continue to be the major focus of stress research, recent studies suggest that chronic stress should be a more central focus. An evaluation of this issue is presented using data from a large community survey of married men $(\mathrm{n}=819)$ and women $(\mathrm{n}=936)$. Results show that chronic stresses are more strongly related to depressive symptoms than acute stresses in all but one life domain. The interaction patterns exhibited by chronic and acute stresses are predominantly associated with lower levels of depression than those predicted by a main effects model. This pattern suggests that chronic stresses may reduce the emotional effects of acute stresses. Although the processes through which this effect occurs are not clear, it is suggested that anticipation and reappraisal reduce the stressfulness of an event by making its meaning more benign. Implications for future research on chronic and acute stress effects are discussed.

Over the past two decades since Holmes and Rahe's (1967) groundbreaking work on life events and illness, acute life events have been the major focus of psychological stress research. Yet it is becoming increasingly clear that this attention is misplaced and that chronic stress should be a more central focus. When Veroff, Douvan, and Kulka (1981) asked a national sample of

\footnotetext{
${ }^{1}$ This research was sponsored by Training Grant T32 MH16806, by Research Scientist Development Award $1 \mathrm{~K} 02$ MH00507, and by Merit Award 1 M01 MH16806 from the National Institute of Mental Health. We thank our colleagues in the Social Environment and Health Program at the Institute for Social Research for helpful comments on a previous draft of this paper, which was presented at our ongoing Program seminar. We also thank the anonymous reviewers for very helpful comments.

${ }^{2}$ All correspondence should be sent to Ronald C. Kessler, Institute for Social Research, The University of Michigan, Box 1248, Ann Arbor, Michigan 48106-1248.
} 
adults to describe their major sources of stress, chronic situations were mentioned much more often than events. Mattlin, Wethington, and Kessler (1990), in a more recent general population survey, asked respondents to describe their most stressful experience over the past year and found that chronic difficulties were again reported more often than life events. Recent empirical analyses of chronic and acute stress effects have also demonstrated that chronic stress is a stronger predictor of psychological adjustment than acute stress (Avison \& Turner, 1988; Eckenrode, 1984; Mitchell, Cronkite, \& Moos, 1983). The work of Lazarus and DeLongis (1983) documenting a stronger effect of "daily hassles" than major life events on psychological adjustment can be interpreted as consistent with this same pattern, in that many of the hassles in their inventory were indicators of ongoing role-related stresses.

Furthermore, several recent studies suggest that chronic stress can help explain the relationship between life events and psychological adjustment. In a study of working-class women, Brown and Harris (1978) found that chronic stresses of a variety of sorts can magnify the effects of life events on clinical depression. Pearlin, Lieberman, Menaghan, and Mullan (1981) demonstrated that the relationship between life events and depression occurs through the exacerbation of chronic role-related strains. Drawing on results such as these, several investigators have called for more serious study of the joint effects of chronic and acute stress (Costello, 1982; Mitchell et al., 1983; Wheaton, 1983, 1990).

The results of such an analysis are presented in this report. Unlike most prior investigations, we base our analysis on a data collection scheme that generates parallel information about a wide range of both chronic and acute stresses, thus allowing us to assess their relative effects on psychological functioning in an even-handed fashion. Substantive disaggregation is used to make domain-specific comparisons. We also investigate the possibility, suggested by Brown and Harris (1978), that chronic difficulties modify the effects of life events on distress. All of these analyses are carried out in a large population survey of married men and women designed to elicit broad-based information about the occurrence of major life events and chronic stresses.

\section{METHOD}

\section{The Sample}

Data were obtained from face-to-face interviews with 1,755 respondents in the Detroit metropolitan area in the spring and summer of 1985. All respondents were married and living in noninstitutionalized housing at the time of interview. Interviews took place in respondents' homes. Selection of households was made in a multistage stratified cluster design that gave each mar- 
ried person in the sampling frame an equal probability of selection. The screening response rate (which determined eligibility for the study) was $98 \%$, and $78 \%$ of eligible respondents were successfully interviewed in screened households, for an overall response rate of $76 \%$. Respondents were eligible if at least one member of the couple was between the ages of 18 and 65 at the time of the interview. Only nonblack couples were included in the survey. No attempt was made to interview respondents who had trouble speaking English, were senile, or who had a physical illness that made completion of the interview burdensome.

Demographic characteristics of the sample closely reflect those of the target population. Mean age was 42 years, mean education 13 years, and mean household income (in 1984 dollars) $\$ 41,800$. This high average income, which accurately corresponds to the population data for nonblack couples in the Detroit metropolitan area, reflects the fact that the vast majority of men $(84 \%)$ were employed full-time and a large proportion of women $(48 \%)$ were employed at least 20 hours a week.

\section{Depressive Symptoms}

Depression was assessed by the 10-item depression subscale of the revised Hopkins Symptom Checklist (HSCL; Derogatis, 1977). Respondents rated the frequency with which each symptom occurred in the 30 days prior to the interview using a 4-point scale, ranging from never to very often. Representative items include "How often have you felt worthless?" and "How often have you felt sad or blue?" The scale was scored by standardizing each item to a mean of zero and a variance of 1 , summing across all the items, and then standardizing the total. Alpha reliability is .83 for men and .84 for women.

\section{Chronic and Acute Stress}

Conventional life event surveys usually ask respondents to read a long list of events and endorse those that occurred to them over a specified time period. Sums of the life events on the list are then used as the measure of stress exposure. We modified this approach in several ways. First, we created a series of short life event lists rather than one long list. Each list focused on events in a particular domain of life (e.g., physical illness, financial difficulty, death of a loved one). The lists were interspersed throughout the interview schedule rather than presented together. The purpose of this modification was to avoid creating the "no" response set that can otherwise occur when respondents are asked to consider a single long list of questions (Sud- 
man \& Bradburn, 1974). We also hoped to help trigger a memory schema that would facilitate recall (Higgins, Rholes, \& Jones, 1977) by focusing each short list on a particular domain of life. Each short event list was included in a section of the interview that asked other questions about the life domain in an extra effort to create a context that would stimulate recall.

The questions included in this series of short lists were based on items developed originally by Brown and Harris (1978) and by B. S. Dohrenwend, Krasnoff, Askenasy, and Dohrenwend (1978). Questions were included about a total of 87 stresses in all, aimed at covering the major domains of serious stress captured in these previous inventories. Probes were used to obtain information about the context of events. Stress severity ratings were based on the rating scheme developed by Brown and Harris (1978). Only events in the highest two categories of severity in the Brown and Harris scheme are considered in the following analyses.

As in previous surveys of life stress, some of the items in our lists dealt with stresses that could be ongoing rather than acute, such as "a lifethreatening illness" or "serious marital difficulties." When a respondent reported such a stress, we asked whether this situation had begun in the past 12 months or had been going on longer. If the latter, we asked whether there had been a major change in the situation during the past 12 months and, if so, whether the change was for the better of worse. A chronic stress was defined as one that began more than 12 months before the interview. An acute stress was defined as one that started within 12 months of the interview. All point-in-time events (e.g., the death of a loved one, job loss) were coded as acute stresses. Ongoing situations created by point-in-time events (e.g., financial difficulties created by job loss) were coded as chronic if the events that caused them had occurred more than 12 months before the interview. Two separate stresses, one chronic and the other acute, were coded when a respondent reported the existence of an ongoing stress situation (e.g., a troubled marriage) that had significantly changed for the worse (e.g., marital separation) during the past 12 months.

Given our interest in comparing chronic and acute stresses, questions in our stress lists that touched on potentially chronic situations were consciously phrased to remove the time referent found in typical life event inventories. For example, the B. S. Dohrenwend et al. (1978) life event inventory includes an entry for "relations with spouse/mate changed for the worse," but no entry for ongoing marital difficulties. We attempted to measure both types of stress in this domain by asking about "serious marital difficulties" and probing positive responses for content and duration.

This approach retains the problem of subjectivity inherent in the determination of what constitutes a "serious" difficulty. Many of the questions that elicit information about chronic stresses have a subjective component 
of this sort. Previous research on the reliability of life event reports has shown that questions that contain such qualifiers are assessed less reliably than those that can be defined more objectively (e.g., death, divorce, job loss; Neugebauer, 1981). This raises the possibility that selective perceptions, based either on current level of depression or on individual differences linked to chronic depression (e.g., negative affectivity; Watson \& Pennebaker, 1989), might play a larger part in reports about chronic stresses than acute stresses. This issue is discussed at the end of the paper in a consideration of limitations.

Summary chronic and acute stress scales were created in a two-step fashion. In the first step, a series of five domain-specific stress measures was generated for each respondent. The domains, which are the subject of more disaggregated analyses in a later section of the paper, include physical illness, financial difficulty, marital conflict, other interpersonal conflict, and death of a loved one. These domains capture the vast majority of the serious stresses reported in the survey. Each domain-specific measure was dichotomized to discriminate between respondents who had no stresses in the domain from those who had one or more.

In the second step, summary chronic stress and acute stress scores were created by summing the number of domains in which each respondent reported one or more stresses. These summary scores are very highly correlated with more conventional summary measures that simply sum up all chronic or acute stresses across domains (Pearson correlations of .95 for chronic and .93 for acute stress). We chose to use the less conventional measures, though, because preliminary analyses showed that the increase in depressive symptoms associated with multiple stresses compared to only a single stress within a single domain is considerably smaller than the increase associated with a single stress compared to no stress within a single domain. The conventional summary measure, which simply sums stresses across domains, implicitly equates multiple stresses in a single domain with a single stress in each of multiple domains. Our measure does not.

\section{RESULTS}

\section{The Disaggregation of Chronic and Acute Stress}

Table I presents the means and standard deviations of the summary chronic and acute stress scales. Women are exposed to acute stresses in more domains than men, $t(1752)=-1.7, p<.10$, although this difference is only marginally significant.

Table II presents the results of regression analyses in which chronic stress, acute stress, and control variables (age, employment status, educa- 
Table I. Exposure to Chronic and Acute Stresses Among Men and Women ${ }^{a}$

\begin{tabular}{|c|c|c|c|c|}
\hline \multirow[b]{2}{*}{ Type of stress } & \multicolumn{2}{|c|}{$\begin{array}{c}\text { Men } \\
(n=819)\end{array}$} & \multicolumn{2}{|c|}{$\begin{array}{c}\text { Women } \\
(n=936)\end{array}$} \\
\hline & $M$ & $S D$ & $M$ & $S D$ \\
\hline Chronic & .374 & .603 & .402 & .611 \\
\hline Acute & .391 & .594 & .441 & .647 \\
\hline
\end{tabular}

${ }^{a}$ Means are the average number of domains in which at least one stress was reported.

tional level, and two dichotomous variables for the presence of preschool or older children in the home) were used to predict depressive symptoms. We find that both chronic and acute stress significantly predict depression among men, $b=.295, t(813)=5.5, p<.05$ and $b=.145, t(813)=2.7$, $p<.05$, and among women, $b=.480, t(933)=8.9, p<.05$ and $b=.196$, $t(933)=3.9, p<.05$. The unstandardized regression coefficients can be interpreted as suggesting that each additional chronic stress domain increases depressive symptoms by 0.295 standard deviation units among men and 0.480 standard deviation units among women, while each additional acute stress domain increases depressive symptoms 0.145 standard deviation units among men and 0.196 standard deviation units among women.

An evaluation of the statistical significance of the difference in the regression coefficients associated with chronic and acute stress was carried out by estimating revised regression equations with contrast codes (J. Cohen \& Cohen, 1983). The results of this analysis indicate that for both men and women, chronic stress is a stronger predictor of depressive symptoms than acute stress, $\Delta b=.150, t(813)=1.8, p<.06$ among men and $\Delta b$ $=.284, t(933)=3.6, p<.05$, among women, although the difference for

Table II. Estimated Unstandardized Regression of Depressive Symptoms on Chronic and Acute Stress for Men and Women $^{\alpha}$

\begin{tabular}{|c|c|c|c|c|}
\hline \multirow[b]{2}{*}{ Type of stress } & \multicolumn{2}{|c|}{$\begin{array}{c}\text { Men } \\
(n=819)\end{array}$} & \multicolumn{2}{|c|}{$\begin{array}{c}\text { Women } \\
(n=936)\end{array}$} \\
\hline & $b$ & $t$ & $b$ & $t$ \\
\hline Chronic & .295 & $5.5^{b}$ & .480 & $8.9^{b}$ \\
\hline Acute & .145 & $2.7^{b}$ & .196 & $3.9^{b}$ \\
\hline Difference & .150 & 1.8 & .284 & $3.6^{b}$ \\
\hline
\end{tabular}

${ }^{a}$ Coefficients are based on the number of domains in which at least one stress occurred. Adjusted $R^{2}=.087$ for men and .112 for women.

${ }^{b} p<.05$, two-tailed. 
men is only marginally significant. There is no sex difference in the impact of acute stress on depression, $\Delta b=.051, t(1746)=0.7, p=\mathrm{ns}$. The association of depression with chronic stress is nearly two times stronger among women than among men, $\Delta b=.185, t(1746)=2.4, p<.05 .{ }^{3}$

It is important to remember, in this context, that the data collection strategy used to elicit information about chronic and acute stresses focused on serious stresses (those rated in the highest two categories of the Brown and Harris rating scheme) across a range of stress domains. This means that the results in Table II can be interpreted as showing that the typical serious chronic stress is more strongly related to depression than the typical serious acute stress, not that all chronic stresses are more important than all acute stresses. For example, the emotional consequences resulting from an acute stress such as a rape are no doubt more severe than the effects of many serious chronic stresses.

\section{Exposure to Chronic versus Acute Stress by Substantive Domain}

The large sample makes it possible to explore associations among disaggregated measures of chronic and acute stress. This was done by creating five subscales of the most common stress types. As noted earlier, these five categories are physical illness, financial difficulty, marital conflict, other interpersonal conflict, and death of a loved one. Most of the events that constitute these categories are diverse. Financial difficulty, for example, includes such things as being fired, business failure, foreclosure of a mortgage (all defined as acute), and ongoing problems meeting regular financial obligations (a chronic stress). Interpersonal conflict includes such things as a broken engagement, termination of other important relationships, problems getting along with supervisors or co-workers, etc.

We recognize that concentration on these comparatively common stress domains fails to capture the full complexity found in a more comprehensive aggregate analysis of stress effects. We also recognize that the combination of diverse events into these five substantive clusters masks important variability among stresses, both in their meanings and their emotional effects. However, this partial disaggregation is more true to reality than the conventional approach of combining all stresses into one summary measure. It is sufficiently detailed to capture important substantive specifications of aggregate effects. It is also more feasible than a totally disaggregated analysis

${ }^{3}$ One possible interpretation of this sex difference is that women have a larger average number of chronic stresses within the domains where they experience this type of stress. We investigated this possibility and found no evidence to support it. 
Table III. Exposure to Chronic and Acute Stresses by Substantive Domain and Their Difference for Men and Women $^{a}$

\begin{tabular}{|c|c|c|c|c|}
\hline \multirow[b]{2}{*}{ Type of stress } & \multicolumn{2}{|c|}{$\begin{array}{c}\text { Men } \\
(n=819)\end{array}$} & \multicolumn{2}{|c|}{$\begin{array}{c}\text { Women } \\
(n=936)\end{array}$} \\
\hline & $M$ & $S D$ & $M$ & $S D$ \\
\hline \multicolumn{5}{|l|}{ Physical illness } \\
\hline Chronic & .092 & .289 & .090 & .286 \\
\hline Acute & .076 & .265 & .077 & .267 \\
\hline Difference $(\Delta M)$ & \multicolumn{2}{|c|}{.016} & \multicolumn{2}{|c|}{.013} \\
\hline$t$ Difference & \multicolumn{2}{|c|}{1.3} & \multicolumn{2}{|c|}{1.1} \\
\hline \multicolumn{5}{|l|}{ Financial difficulty } \\
\hline Chronic & .057 & .233 & .060 & .237 \\
\hline Acute & .096 & .295 & .085 & .280 \\
\hline Difference $(\Delta M)$ & \multirow{2}{*}{\multicolumn{2}{|c|}{$\begin{array}{c}-.039 \\
-3.3^{b}\end{array}$}} & \multirow{2}{*}{\multicolumn{2}{|c|}{$\begin{array}{l}-.025 \\
-2.4^{b}\end{array}$}} \\
\hline$t$ Difference & & & & \\
\hline \multicolumn{5}{|l|}{ Marital conflict } \\
\hline Chronic & .090 & .287 & .094 & .292 \\
\hline Acute & .046 & .210 & .067 & .251 \\
\hline Difference $(\Delta M)$ & \multicolumn{2}{|c|}{.044} & \multicolumn{2}{|c|}{.027} \\
\hline$t$ Difference & \multicolumn{2}{|c|}{$3.9^{b}$} & \multicolumn{2}{|c|}{$2.3^{b}$} \\
\hline \multicolumn{5}{|l|}{$\begin{array}{l}\text { Interpersonal } \\
\text { conflict }\end{array}$} \\
\hline Chronic & .134 & .341 & .158 & .365 \\
\hline Acute & .072 & .259 & .102 & .302 \\
\hline Difference $(\Delta M)$ & \multicolumn{2}{|c|}{.062} & \multicolumn{2}{|c|}{.056} \\
\hline$t$ difference & \multicolumn{2}{|c|}{$4.3^{b}$} & \multicolumn{2}{|c|}{$3.7^{b}$} \\
\hline \multicolumn{5}{|l|}{$\begin{array}{l}\text { Death of a loved } \\
\text { one }\end{array}$} \\
\hline Acute & .100 & .300 & .110 & .313 \\
\hline
\end{tabular}

of the many different events included in the full interview, almost all of which occurred so infrequently that it would be impossible to carry out a statistically powerful analysis of their association with depression.

Table III reports the percentage of respondents who reported the presence of one or more stresses in each of these five broad stress domains. All disaggregated analyses are based on dichotomous measures of presence versus absence of at least one stress in each domain rather than continuous variables because of the extreme skew in all disaggregated measures of stress. The data in Table III underscore the importance of examining event chronicity across substantively diverse domains by showing that chronicity depends on the substantive domain under consideration. For both men and women, chronic marital conflicts $(M=.090$ among men, and $M=.094$ among women) and interpersonal conflicts (.134 among men, and $M=.158$ among women) occur significantly more often than their acute counterparts [for marital conflicts, $M=.046, t(813)=3.9, p<.05$, among men, and 
$M=.067, t(933)=2.3, p<.05$, among women; for interpersonal conflicts, $M=.072, t(813)=4.3, p<.05$, among men, and $M=.102, t(933)$ $=3.7, p<.05$, among women]. Serious financial difficulties, however, are more likely to be acute $(M=.096$ among men, and $M=.085$ among women) than chronic $[M=.057, t(813)=-3.3, p<.05$, among men, and $M$ $=.060, t(933)=-2.4, p<.05$, among women]. Physical illness is the only type of stress considered here that occurs equally often in chronic and acute forms $[M=.092$ and .076 , respectively, $t(813)=1.3, p=\mathrm{ns}$, among men, and $M=.090$ and .077 , respectively, $t(933)=1.1, p=\mathrm{ns,}$, among women]. We also see in this disaggregation that the higher exposure of women than men to aggregate acute stress (Table I) stems largely from significantly more exposure to interpersonal conflicts with family and work colleagues, $t(1752)$ $=-2.2, p<.05$, and marginally with spouses, $t(1752)=-1.9, p<.07$.

\section{Response to Chronic and Acute Stress by Substantive Domain}

Table IV presents results from the regression of depressive symptoms on disaggregated measures of chronic and acute stress and controls, separately

Table IV. Estimated Unstandardized Regression of Depressive Symptoms on Chronic and Acute Stresses by Substantive Domain for Men and Women ${ }^{a}$

\begin{tabular}{|c|c|c|c|c|}
\hline \multirow[b]{2}{*}{ Type of stress } & \multicolumn{2}{|c|}{$\begin{array}{c}\text { Men } \\
(n=819)\end{array}$} & \multicolumn{2}{|c|}{$\begin{array}{c}\text { Women } \\
(n=936)\end{array}$} \\
\hline & $b$ & $t$ & $b$ & $t$ \\
\hline \multicolumn{5}{|l|}{ Physical illness } \\
\hline Chronic & .308 & $2.6^{b}$ & .298 & $2.6^{b}$ \\
\hline Acute & .057 & 0.5 & .033 & 0.3 \\
\hline Difference & .251 & 1.4 & .265 & 1.5 \\
\hline \multicolumn{5}{|c|}{ Financial difficulty } \\
\hline Chronic & .245 & 1.8 & .283 & $2.1^{b}$ \\
\hline Acute & .016 & 0.2 & -.085 & -0.7 \\
\hline Difference & .229 & 1.2 & .368 & 1.9 \\
\hline \multicolumn{5}{|l|}{ Marital conflict } \\
\hline Chronic & .381 & $3.4^{b}$ & .739 & $6.6^{b}$ \\
\hline Acute & .496 & $3.2^{b}$ & .531 & $4.1^{b}$ \\
\hline Difference & -.115 & -0.6 & .208 & 1.2 \\
\hline \multicolumn{5}{|l|}{$\begin{array}{l}\text { Interpersonal } \\
\text { conflict }\end{array}$} \\
\hline Chronic & .239 & $2.5^{b}$ & .496 & $5.6^{b}$ \\
\hline Acute & .117 & 1.0 & .179 & 1.7 \\
\hline Difference & .122 & 0.8 & .317 & $2.2^{b}$ \\
\hline \multicolumn{5}{|c|}{$\begin{array}{l}\text { Death of a loved } \\
\text { one }\end{array}$} \\
\hline Acute & .186 & 1.8 & .308 & $2.9^{b}$ \\
\hline
\end{tabular}

${ }^{a}$ Adjusted $R^{2}=.098$ for men and .139 for women.

${ }^{b} p<.05$, two-tailed. 
for men and women. The results suggest that for both men and women, chronic stress is a stronger predictor than acute stress. Few statistically significant slope differences exist within domains, however, reflecting the fact that the two-level disaggregation leaves us with too few occurrences for statistically powerful analysis. Nonetheless, it is clear that chronic stress is more powerfully associated with depressive symptoms than acute stress. As shown in Table IV, meaningful predictive effects of stress are confined to chronic stress in two domains (physical illness and financial difficulty). Among women, the effect is much larger for chronic than acute stress in a third domain (interpersonal conflict). In only one domain (marital conflict) is there evidence that acute stress has an effect as large as that of chronic stress. Furthermore, the disaggregated analysis shows that the greater effect of aggregate chronic stress among women compared to men (see Table II) is due to chronic interpersonal conflict in marriage and with family and work colleagues, $\Delta b=-.358, t(1752)=-2.2, p<.05$, and $\Delta b=-.257, t(1752)$ $=-1.9, p<.06$, respectively.

\section{The Joint Effects of Chronic and Acute Stress}

\section{Aggregate Patterns}

As noted above, there has been considerable discussion of the possibility that chronic stress can magnify the impact of life events on depression. To evaluate this possibility, we extended the analysis reported in Table II by including a multiplicative interaction between chronic and acute stress in the regression equation. This model was estimated separately for men and women. As shown in Table V, the slopes associated with the interaction effect are negative both among men $[b=-.077, t(813)=-1.0, p=n s]$ and among women, for whom the effect is significant $[b=-.154, t(933)$ $=-2.1, p<.05]$.

Given the counterintuitive sign of this interaction and its potential importance for future research on joint stress effects, it is worth noting that we carried out sensitivity analyses to investigate the possibility that the interaction was created by some anomaly in the data. Underlying nonlinearities in main effects can sometimes give the false appearance of interactions (Cleary \& Kessler, 1982), so we also investigated the effects of nonlinear marginal effects on the interaction. These investigations show that the negative interaction between chronic and acute stress is quite stable and not due to a small number of influential data points, to systematic nonlinearities in the main effects, nor to some combination of these influences. 
Table V. Estimated Unstandardized Regression of the Marginal and Joint Effects of Chronic and Acute Stresses Predicting Depressive Symptoms for Men and Women ${ }^{a}$

\begin{tabular}{lllllr}
\hline & \multicolumn{2}{c}{$\begin{array}{c}\text { Men } \\
(n=819)\end{array}$} & & \multicolumn{2}{c}{$\begin{array}{c}\text { Women } \\
(n=936)\end{array}$} \\
\cline { 2 - 3 } \cline { 5 - 6 } Type of stress & $b$ & $t$ & & $b$ & \multicolumn{1}{c}{$t$} \\
\hline Chronic & .338 & $4.8^{b}$ & & .573 & $8.2^{b}$ \\
Acute & .181 & $2.7^{b}$ & & .275 & $4.4^{b}$ \\
Chronic $\times$ Acute & -.077 & -1.0 & & -.154 & $-2.1^{b}$ \\
\hline
\end{tabular}

${ }^{a}$ Coefficients are based on the number of domains in which at least one stress occurred. Adjusted $R^{2}=.088$ for men and .117 for women. ${ }^{b} p<.05$, two-tailed.

It is possible to interpret this interaction either as evidence that preexisting chronic stress reduces the impact of acute stress on depression or that acute stress ameliorates the effect of chronic stress. The two interpretations are equivalent algebraically. We focus on the first of these two interpretations in the following discussion, but the considerations are the same whichever way one thinks about the interaction. The important point is that the joint occurrence of both stress types is associated with less depression than one would predict based on an additive model.

The marginal effect of either chronic or acute stress in this model can be interpreted as the effect of this stress among respondents who have no stress of the other type. As shown in Table V, all of these marginal effects are significant, which means that both chronic and acute stresses are associated with depressive symptoms in the absence of stresses of the other type. The slopes linking chronic stress in the absence of acute stress with depressive symptoms are, however, stronger than those linking acute stress in the absence of chronic stress with depressive symptoms, both among men, $\Delta b$ $=.157, t(813)=1.6, p=\mathrm{ns}$, and among women, $\Delta b=.298, t(933)=$ $3.2, p<.05$. This is, of course, consistent with the main effects model in Table II.

\section{Disaggregated Patterns}

We also evaluated the significance of disaggregated interactions between particular kinds of chronic and acute stress. Rather than evaluate all 50 logically possible interactions (five types of chronic stress $\times$ five types of acute stress, separately for men and women) in an exploratory fashion, we focused on four broad interaction subtypes that are of particular conceptual interest. 


\section{Within-Domain Patterns}

The first subtype we considered involves interactions of chronic and acute stress within the same life domain, a version of what Brown and Harris (1978) call a "matching" event. There is some reason to believe that interactions of this sort will be positive, indicating that the emotional effect of acute stress is more powerful in the presence of a previously existing stress of a similar sort. This could occur either because the acute stress complicates the chronic situation (as a heart attack, for example, might complicate the treatment of a preexisting chronic medical condition) or because the chronic stress represents a deficit which might magnify the impact of the acute stress (as preexisting financial problems, for example, might heighten the emotional impact of a subsequent job loss). Another possibility is that the chronic stress creates a meaning context which leads to a more negative appraisal of the acute stress.

At the same time, a case could be made for the possibility that some within-domain interactions between chronic and acute stress will be negative. Wheaton (1990), in fact, argued that this will be the case whenever the acute stress is experienced as the end of an ongoing difficulty in the same life domain, as a divorce might represent the end of a troubled marriage (Aseltine \& Kessler, 1990). A negative interaction could also occur if chronic stress in a particular life domain leads to emotional habituation, preemptive coping, or devaluation of a subsequent stress.

To evaluate these possibilities, a regression equation was estimated that contained all the predictors in the disaggregated main effect model (Table IV) plus five within-domain interactions between chronic and acute stress. This model was estimated separately for men and women. Summary results are reported in Table VI. ${ }^{4}$ In general, marginal effects are stronger for chronic than acute stress (in 7 of 10 replications), consistent with the aggregate results. Moreover, for two of the domains, physical illness and financial difficulty, acute stress effects exist only in the presence of chronic stress, whereas chronic stress in each of these domains has a significant and independent effect on depression. It is noteworthy that both chronic and acute stress in the domains of conflict with friends and work colleagues and in marriage have independent effects (although the acute component of conflict with friends and

\footnotetext{
${ }^{4}$ Chronic illness of a loved one is included in this analysis as the acute counterpart of death of a loved one. This chronic illness measure was not included in previous analyses because situations of this sort, while very frequently reported, are generally not found to have strong effects on depression. The Brown and Harris LEDS rating scheme, on which our life event coding scheme is based, would exclude the vast majority of these events from an inventory of major stresses.
} 
Table VI. Estimated Unstandardized Regression of the Marginal and Joint Effects of Within-Domain Chronic and Acute Stresses Predicting Depressive Symptoms for Men and Women ${ }^{a}$

\begin{tabular}{|c|c|c|c|c|}
\hline \multirow[b]{2}{*}{ Type of stress } & \multicolumn{2}{|c|}{$\begin{array}{c}\text { Men } \\
(n=819)\end{array}$} & \multicolumn{2}{|c|}{$\begin{array}{c}\text { Women } \\
(n=: 936)\end{array}$} \\
\hline & $b$ & $t$ & $b$ & $t$ \\
\hline \multicolumn{5}{|l|}{ Physical illness } \\
\hline Chronic & .377 & $2.9^{c}$ & .408 & $3.3^{c}$ \\
\hline Acute & .145 & 1.0 & .161 & 1.2 \\
\hline Chronic $\times$ Acute & -.337 & -1.2 & -.646 & $-2.1^{b}$ \\
\hline \multicolumn{5}{|l|}{ Financial difficulty } \\
\hline Chronic & .146 & 0.9 & .399 & $2.5^{b}$ \\
\hline Acute & -.024 & -0.2 & -.019 & -0.2 \\
\hline Chronic $\times$ Acute & .283 & 0.9 & -.504 & -1.6 \\
\hline \multicolumn{5}{|l|}{ Marital conflict } \\
\hline Chronic & .398 & $3.3^{\mathrm{c}}$ & .697 & $5.8^{c}$ \\
\hline Acute & .534 & $2.9^{c}$ & .499 & $3.4^{c}$ \\
\hline Chronic $\times$ Acute & -.136 & -0.4 & .338 & 1.1 \\
\hline \multicolumn{5}{|l|}{$\begin{array}{l}\text { Interpersonal } \\
\text { conflict }\end{array}$} \\
\hline Chronic & .256 & $2.5^{b}$ & .614 & $6.4^{c}$ \\
\hline Acute & .146 & 1.1 & .346 & $2.9^{c}$ \\
\hline Chronic $\times$ Acute & -.125 & -0.4 & -.783 & $-3.0^{c}$ \\
\hline \multirow{2}{*}{\multicolumn{5}{|c|}{$\begin{array}{l}\text { Chronic illness/ } \\
\text { Death of a loved } \\
\text { one }\end{array}$}} \\
\hline & & & & \\
\hline Chronic (illness) & -.031 & -0.3 & .025 & 0.3 \\
\hline Acute (death) & .251 & 1.9 & .290 & $2.3^{b}$ \\
\hline Chronic $\times$ Acute & -.171 & -0.7 & .036 & 0.2 \\
\hline
\end{tabular}

${ }^{a}$ Adjusted $R^{2}=.102$ for men and .156 for women.

${ }^{b} p<.05$, two-tailed.

${ }^{c} p<.05$ for $t>2.6$.

work colleagues is not significant for men), consistent with other research implicating the role of interpersonal conflict in psychological distress (Bolger, DeLongis, Kessler, \& Schilling, 1989).

The interaction effects in this model can be interpreted as the deviations of observed associations from those expected by the main effects model. Seven of these 10 interactions are negative and 2 of the negative interactions (both of them among women) are significant at $p<.05$ : the interactive effects of chronic and acute interpersonal conflict, $b=-.783, t(933)=-3.0$, $p<.05$, and of chronic and acute physical illness, $b=-.646, t(933)=$ $-2.1, p<.05$. By chance alone, we would expect that in a set of $10 \mathrm{com}-$ parisons, less than 1 of them would be significant, so it is unlikely that the 2 we observe here are significant by chance. When adjusted for simultaneous significance, the interactive effect of interpersonal conflict remains significant at $p<.05(t>2.6)$. 
This pattern of interactions can be interpreted either as evidence that chronic stress buffers the emotional impact of acute stress or that acute stress dampens the effect of chronic stress. ${ }^{5}$ In either case it is possible to interpret the generally negative pattern, after the fact, as due to anticipation or to prior devaluation or to coping preparedness, but none of these general explanations suggests why the interactions occur more strongly among women than men, nor why they exist for some stress domains and not others.

\section{Patterns Involving Chronic Interpersonal Conflict}

There is a vast literature showing that the effects of stressful life events are significantly less pronounced among people with access to supportive social relationships than among those whose relationships are not supportive (e.g., S. Cohen \& Wills, 1985; Kessler \& McLeod, 1984). One might, by extension, hypothesize that people with chronic interpersonal conflict would be particularly vulnerable to the effects of stress. There has been some recent interest in the social support literature in investigating the effects of these more negative social relationships on health (Abbey, Abramis, \& Caplan, 1985; Fiore, Becker, \& Coppel, 1983; Pagel, Erdly, \& Becker, 1987; Riley \& Eckenrode, 1986; Rook, 1984; Schuster, Kessler, \& Aseltine, 1990).

These investigations have consistently documented a substantially stronger effect of negative social interactions on mood compared to supportive interactions. There has been much less evidence, however, to suggest that negative social relationships exacerbate the effect of life events on mood as powerfully as supportive interactions ameliorate this effect. On the basis of this previous evidence, we hypothesized that there would not be significant interactions between our measures of chronic interpersonal stress and acute stress from other life domains.

\footnotetext{
${ }^{5} \mathrm{~A}$ reviewer suggested an interpretation of a more methodological nature. As noted above, we coded both first occurrences of acute stresses (such as a heart attack occurring to a person with no previous history of heart disease) and significant worsenings (such as a second heart attack occurring to a person with a prior history of heart disease) as acute stresses. The reviewer suggested that the negative interactions found between chronic and acute stresses - which, by definition, include all the worsenings in addition to unrelated chronic and acute stresses in the same life domain (such as a first heart attack occurring to a person with a prior history of some serious health problem other than heart disease) - could reflect the fact that worsenings are less stressful than first occurrences of acute stress. We evaluated this hypothesis by reanalyzing the disaggregated models in Table VI and found that the pattern of negative interactions exists both for first occurrences and worsenings. It should be noted that the acute stresses in the domain of physical illness were mostly first occurrences, as one would expect in a fairly young sample. Most acute financial stresses were also first occurrences. Most acute interpersonal conflicts and deaths, in comparison, were worsenings.
} 
Table VII. Estimated Unstandardized Regression of the Joint Effects of Chronic Interpersonal Conflicts and Acute Stresses Predicting Depressive Symptoms for Men and Women ${ }^{\alpha}$

\begin{tabular}{|c|c|c|c|c|}
\hline \multirow[b]{2}{*}{ Type of stress } & \multicolumn{2}{|c|}{$\begin{array}{c}\text { Men } \\
(n=819) \\
\end{array}$} & \multicolumn{2}{|c|}{$\begin{array}{c}\text { Women } \\
(n=936)\end{array}$} \\
\hline & $b$ & $t$ & $b$ & $t$ \\
\hline \multicolumn{5}{|c|}{ Model 1} \\
\hline $\begin{array}{l}\text { Chronic marital conflict } \\
\text { Acute physical illness } \\
\text { Acute financial difficulty } \\
\text { Acute interpersonal conflict } \\
\text { Acute death of a loved one }\end{array}$ & $\begin{array}{l}.494 \\
.198 \\
.024 \\
.153 \\
.196\end{array}$ & $\begin{array}{l}3.6^{b} \\
1.5 \\
0.2 \\
0.1 \\
1.7\end{array}$ & $\begin{array}{l}.891 \\
.028 \\
.022 \\
.275 \\
.346\end{array}$ & $\begin{array}{l}6.3^{b} \\
0.2 \\
0.2 \\
2.3^{b} \\
3.0^{b}\end{array}$ \\
\hline $\begin{array}{l}\text { Chronic marital conflict } \\
\times \text { Physical illness } \\
\times \text { Financial difficulty } \\
\times \text { Interpersonal conflict } \\
\times \text { Death of a loved one }\end{array}$ & $\begin{array}{r}-.530 \\
.176 \\
.005 \\
.319\end{array}$ & $\begin{array}{r}-1.5 \\
0.4 \\
0.0 \\
0.8\end{array}$ & $\begin{array}{r}.335 \\
-.355 \\
-.389 \\
.079\end{array}$ & $\begin{array}{r}0.9 \\
-0.9 \\
-1.2 \\
0.2\end{array}$ \\
\hline \multicolumn{5}{|c|}{ Model 2} \\
\hline $\begin{array}{l}\text { Chronic interpersonal conflict } \\
\text { Acute physical illness } \\
\text { Acute financial difficulty } \\
\text { Acute marital conflict } \\
\text { Acute death of a loved one }\end{array}$ & $\begin{array}{l}.365 \\
.184 \\
.049 \\
.686 \\
.280\end{array}$ & $\begin{array}{l}3.2^{b} \\
1.3 \\
0.4 \\
3.9^{b} \\
2.4^{b}\end{array}$ & $\begin{array}{r}.564 \\
.098 \\
-.010 \\
.544 \\
.415\end{array}$ & $\begin{aligned} & 5.2^{b} \\
& 0.7 \\
&-0.1 \\
& 3.6^{b} \\
& 3.6^{b}\end{aligned}$ \\
\hline $\begin{array}{l}\text { Chronic interpersonal conflict } \\
\times \text { Physical illness } \\
\times \text { Financial difficulty } \\
\times \text { Marital conflict } \\
\times \text { Death of a loved one } \\
\end{array}$ & $\begin{array}{r}-.260 \\
.048 \\
-.296 \\
-.653 \\
\end{array}$ & $\begin{array}{r}-0.9 \\
0.2 \\
-0.8 \\
-2.1^{b}\end{array}$ & $\begin{array}{r}.114 \\
-.183 \\
.474 \\
-.655 \\
\end{array}$ & $\begin{array}{r}0.4 \\
-0.6 \\
1.5 \\
-2.2^{b} \\
\end{array}$ \\
\hline
\end{tabular}

${ }^{a}$ Adjusted $R^{2}$ for Models 1 and 2 are .078 and .070 for men, and .090 and .090 for women, respectively.

${ }^{b} p<.05$, two-tailed.

The results of analyses evaluating this hypothesis are presented in Table VII. The two prediction equations on which these results are based are similar in structure to the equation that generated the results in Table VI. The main effects of all chronic and acute stresses, plus controls, were included as predictors along with eight interaction terms: four involving the joint effects of chronic marital conflicts and acute stresses in each of the other four domains, and four involving the joint effects of chronic interpersonal conflicts with other family and/or work colleagues and acute stresses in the other four domains. As shown in Table VII, the marginal effects of chronic marital and interpersonal conflict are generally stronger than the effects of the acute stresses, consistent with the aggregate results. Inspection of interaction terms shows that half are positive and half are negative. Only 
2 of 16 (8 interactions separately for men and women) are significant at $p$ $<.05$ and both of these are negative.

The two significant interactions occur independently for the same pair of stresses in the subsamples of men and women. The death of a loved one, in both these samples, has a significantly less powerful effect on depression among respondents who report previously existing interpersonal conflicts in their social networks; $b=-.653, t(813)=-2.1, p<.05$, among men, $b=-.655, t(933)=-2.2, p<.05$, among women. It should be noted, though, that when adjusted for simultaneous significance, neither effect remains significant $(t<2.5)$. A plausible after-the-fact interpretation of this pattern, assuming it is real, is that network losses are less distressing to people who are not close to their networks than to people who are closely involved in their networks. There is some previous evidence about the effects of network events consistent with this interpretation (Kessler \& McLeod, 1984).

\section{Patterns Involving Chronic Physical Illness}

According to B. P. Dohrenwend (1979), physical disability is a consistent feature in the kinds of severe chronic stress that create emotional breakdown in virtually all who are exposed to it. Dohrenwend contends that chronic physical disability is part of a multiple stress syndrome associated with particularly strong vulnerabilty to acute stress. Therefore, we hypothesized that chronic physical illness would exacerbate the impact of acute stress on depression in our sample.

Results of the model that evaluated this hypothesis are reported in Table VIII. An examination of the marginal effects shows that the effect of chronic physical illness in the absence of an acute stress is not consistently stronger than the independent acute stress effects. Indeed, in the absence of an acute stress, chronic physical illness does not have a significant emotional effect. Acute stress in the form of marital conflict and death of a loved one for women have independent effects on depression, consistent with the additive model presented in Table IV.

Inspection of the interaction terms shows that 7 out of 10 are positive, consistent with our hypothesis. One of these positive interactions (among men) is significant at $p<.05$ : the interactive effect of chronic physical illness and the death of a loved one, $b=.770, t(813)=2.5, p<.05$. One other interaction, also among men, is marginally significant: chronic physical illness and acute interpersonal conflict, $b=.777, t(813)=1.6, p<.10$. When adjusted for simultaneous significance, neither effect is statistically significant $(t<2.5)$; however, the observed pattern of slopes is consistently 
Table VIII. Estimated Unstandardized Regression of the Joint Effects of Chronic Physical Illness and Acute Stresses Predicting Depressive Symptoms for Men and Women ${ }^{a}$

\begin{tabular}{|c|c|c|c|c|}
\hline \multirow[b]{2}{*}{ Type of stress } & \multicolumn{2}{|c|}{$\begin{array}{c}\begin{array}{c}\text { Men } \\
(n=819)\end{array} \\
\end{array}$} & \multicolumn{2}{|c|}{$\begin{array}{c}\text { Women } \\
(n=936)\end{array}$} \\
\hline & $b$ & $t$ & $b$ & $t$ \\
\hline Chronic physical illness & .159 & 1.2 & .257 & 1.9 \\
\hline Acute financial difficulty & .050 & 0.4 & -.035 & -0.3 \\
\hline Acute marital conflict & .557 & $3.5^{b}$ & .709 & $5.2^{b}$ \\
\hline Acute interpersonal conflict & .075 & 0.6 & .192 & 1.6 \\
\hline Acute death of a loved one & .052 & 0.4 & .310 & $2.7^{b}$ \\
\hline \multicolumn{5}{|l|}{ Chronic physical illness } \\
\hline$\times$ Financial difficulty & .143 & 0.4 & .086 & 0.2 \\
\hline$\times$ Marital conflict & .910 & 1.3 & -.612 & -0.8 \\
\hline$\times$ Interpersonal conflict & .777 & 1.6 & .414 & 1.2 \\
\hline$x$ Death of a loved one & .770 & $2.5^{b}$ & .127 & 0.4 \\
\hline
\end{tabular}

${ }^{a}$ Adjusted $R^{2}=.084$ for men and .061 for women.

${ }^{b} p<.05$, two-tailed.

in the predicted direction and substantial in magnitude, particularly among men. Thus, we have some reason to believe that these effects are meaningful ones.

It is noteworthy that both of these effects (i.e., chronic physical illness with death of a loved one, and chronic physical illness with interpersonal conflict) have an interpersonal component. This suggests that the stressexacerbating effects of chronic illness may be implicated in interpersonal loss in some way, perhaps because chronic illness creates problems of social isolation that magnify the importance of these types of events. The perplexing aspect of this, though, is that the interactions exist for men rather than women. We generally find that interpersonal issues are more important for women's adjustment than for men's (e.g., Kessler \& McLeod, 1984). Unfortunately, we do not have enough detailed information to clarify why this effect is confined to male respondents.

\section{Patterns Involving Chronic Financial Difficulty}

The remaining interactions considered here involve ongoing financial difficulty. On a superficial level, one could argue that a chronic stress of this sort would magnify the effects of acute stress on depression. Certainly this is consistent with general thinking that money is a flexible and broadly useful coping resource (Horwitz, 1984) as well as with evidence that lower socioeconomic status is associated with high vulnerability to the effects of stressful life events (Kessler \& Cleary, 1980). 
However, a deeper analysis suggests that financial difficulty is not involved in modifying the effects of other stressful life experiences. First, disaggregated analyses of the relationship between socioeconomic status and depression show that education is much more important than income (Kessler, 1982). This is also true in analyses that disaggregate the component of social class that is associated with stress reactivity (McLeod \& Kessler, 1990). Second, focused analyses of people exposed to chronic financial difficulty due to job loss show that financial difficulty does not modify the effects of other stresses on mood (Kessler, Turner, \& House, 1989). Based on these prior analyses, we hypothesized that there would not be a significant magnifying effect of chronic financial stress on the relationship between acute stress and depression.

Results of the analyses are reported in Table IX. Consistent with patterns observed earlier, the marginal effect of chronic financial difficulty is stronger than the effects of the acute stresses, with the exception of acute marital conflict, for both men and women. Moreover, all acute stresses but one, physical illness, have significant effects in the absence of chronic stress.

An examination of the interaction effects shows that there are no meaningful positive interactions between chronic financial stress and other kinds of stress. Indeed, five of the eight interactions in the table are negative, as is the only significant interaction. Among women, the death of a loved one has a significantly less powerful emotional effect if it occurs in the context of prior financial difficulty, $b=-.955, t(933)=-2.0, p<$ .05 . This interaction is also negative and comparable in magnitude among men, $b=-.848, t(813)=-1.5, p=$ ns. But when we evaluate the significance of the coefficient using an adjustment for simultaneous tests, the effect among women is no longer statistically significant.

Although we did not hypothesize the existence of a significant negative interaction, and do not have a priori interpretations of it, it seems possible that the interaction is a meaningful one because it appears among both men and women. One interpretation is that a death that occurs in the context of a chronic financial stress alleviates depression through its relief of medical expenses. We examined the validity of this interpretation by using information on stress resolution to compare the number of respondents who have resolved a chronic financial difficulty as a function of whether or not they experienced a death. For our interpretation to be valid we would expect financial stress resolution to be associated with a death. This hypothesis is not supported though, as respondents who report a death do not differ in the frequency with which they have resolved a chronic financial difficulty.

Another post hoc interpretation of the negative interaction between chronic financial difficulty and death is possible. A loved one's death can give rise to a reassessment of the meaning and purpose of life (Brown \& Har- 
Table IX. Estimated Unstandardized Regression of the Joint Effects of Chronic Financial Difficulty and Acute Stresses Predicting Depressive Symptoms for Men and Women ${ }^{a}$

\begin{tabular}{lrrrrrr}
\hline & \multicolumn{2}{c}{$\begin{array}{c}\text { Men } \\
(n=819)\end{array}$} & & \multicolumn{2}{c}{$\begin{array}{c}\text { Women } \\
(n=936)\end{array}$} \\
\cline { 2 - 3 } \cline { 6 - 7 } Type of stress & $b$ & $t$ & & $b$ & $t$ \\
\hline Chronic financial difficulty & .400 & $2.6^{b}$ & & .479 & $2.9^{b}$ \\
Acute physical illness & .174 & 1.4 & & .177 & 1.4 \\
Acute marital conflict & .616 & $3.9^{b}$ & & .687 & $4.8^{b}$ \\
Acute interpersonal conflict & .122 & 0.9 & & .242 & $2.1^{b}$ \\
Acute death of a loved one & .235 & $2.1^{b}$ & & .381 & $3.4^{b}$ \\
Chronic financial difficulty & & & & & \\
$\times$ Physical illness & -.320 & -0.3 & & -1.01 & -1.6 \\
$\times$ Marital conflict & -.243 & -0.3 & & .007 & 0.0 \\
$\times$ Interpersonal conflict & .021 & 0.0 & & .277 & 0.4 \\
$\times$ Death of a loved one & -.848 & -1.5 & & -.955 & $-2.0^{b}$ \\
\hline
\end{tabular}

${ }^{a}$ Adjusted $R^{2}=.072$ for men and .067 for women.

${ }^{b} p<.05$, two-tailed.

ris, 1978; Silver \& Wortman, 1980). In this light, a financial difficulty may be reappraised as less important and threatening. Unfortunately, we do not have data to examine the validity of this interpretation.

\section{DISCUSSION}

Our analysis documents two main results that warrant further discussion. First, we document that chronic stress more powerfully predicts depressive symptoms than acute stress. Disaggregation shows that this is true not only on average but also for most major stress domains. Second, we find there is a general pattern of negative interactions between chronic and acute stress in predicting depression. This implies that the depression created by acute stress is, in general, less pronounced among people who have preexisting chronic difficulties than among those without such difficulties. Disaggreagated analyses document some differentiation of this modifying effect across stress domains.

\section{The Effects of Chronic and Acute Stress}

The first of these two findings suggests that the near-exclusive emphasis of stress research on life events has been misplaced. Chronic stresses appear to be more important predictors of depression, as measured in the 
Hopkins Symptom Checklist, than acute stresses. This is true not only in terms of variance explained but also in terms of unstandardized regression coefficients, which means that the structural effects of chronic stresses are larger than those of acute stresses. This is an important point because it speaks to the observation of Depue and Monroe (1986) that the variance in depression screening scales may be more substantially due to chronic minor depression than to episodic major depression. If this observation is correct, it should not be surprising that chronic stresses explain more variance in depression than do acute stresses. This observation cannot provide as obvious an explanation, however, for the fact that the structural effects of chronic stresses - the amount of change in an individual's depression score associated with the occurrence of these stresses - are so much larger than the structural effects of acute stresses.

At least two substantive interpretations exist for the greater structural effects of chronic stresses. One stands on its head the conventional notion that change is an important dimension of stress (e.g., Rahe, 1969) and argues, instead, that problematic situations are most stressful when they are persistent. This interpretation is consistent with Brown and Harris's (1978) work on contextual models of stress effects, which showed that long-term threat is the core dimension of stress associated with the onset of major depression. It is also consistent with several theoretical perspectives on the stress process. If a stress has been ongoing for a long time, coping efforts have almost certainly been unsuccessful and this is likely to lead to an appraisal of the stress as more threatening (Lazarus \& Folkman, 1984) as well as to an attribution of the cause as more stable (Abramson, Seligman, \& Teasdale, 1978) and uncontrollable (Thoits, 1983), all of which are thought to increase the depression associated with stress. Future research on chronic and acute stress effects could evaluate this interpretation by obtaining information on coping, appraisal, and attributions associated with stresses of both types.

A second line of interpretation is also plausible. In our data as well as in those of other investigators (Avison \& Turner, 1988), severe stresses that began during the 12 months prior to the interview are much more likely to be resolved at the time of the interview than stresses that began earlier. The greater impact of chronic stress than acute stress on depressive symptoms, then, might actually reflect a greater impact of ongoing stress than resolved stress.

Both lines of interpretation suggest that persistence of stress - failure to resolve stress - plays some part in explaining the stronger association with depression of chronic stress than acute stress. Both interpretations have the potential to be confounded with selection effects, whereby depression interferes with the ability to resolve stress. Prior research has documented that 
this sort of selection can powerfully affect conclusions about the relative impact of ongoing versus resolved stress on mood (Kessler et al., 1989). Panel data are required to address this problem. Selection is discussed in more detail at the end of the paper in a review of limitations of the analysis.

\section{Interactive Stress Effects}

As noted above, Brown and Harris (1978) argued that chronic difficulties can exacerbate the effects of life events on clinical depression. If a similar process is also operative for the kind of depressive symptoms we study here, we would expect to find pervasive evidence of positive interactions between chronic and acute stresses. Yet we find no such evidence. Indeed, aggregate analyses document a significant negative interaction among women and a nonsignificant, but substantively similar, interaction among men. Disaggregated analyses document that 7 of 10 within-domain interactions are negative and often larger than their associated main effects.

It is noteworthy that the magnitudes of the interactions are as large as those typically found in studies of social support and other widely studied stress buffers (S. Cohen \& Willis, 1985). This means that chronic stresses are as potent as the modifiers that have been the focus of considerable interest among stress researchers over the past decade. Yet, with a few exceptions (e.g., Caspi, Bolger, \& Eckenrode, 1987; Wheaton, 1990), the stress-buffering effects of chronic stress have not been explored.

At least three interpretations of the generally negative modifying effects found in our analyses are consistent with the data. One is that adversity facilitates the development of coping resources which are associated with resilience to subsequent stress. Elder (1974) documented a process of this sort when he showed that people who were exposed to the hardships of the Great Depression as children developed a generalized sense of personal competence which enhanced their coping efficacy later in life.

A second possibility is that enmeshment in an ongoing stressful situation at the time a subsequent acute stress occurs leads to more rapid mobilization of coping resources than would occur in the absence of a prior ongoing stress. Some discussion of this possibility can be found in the literature on anticipation as a determinant of life event effects (Thoits, 1983). A similar theme can be found in theoretical discussions of multiple role stresses, which argue that exposure to stress in one domain can promote coping vigilance in another domain (Marks, 1977; Thoits, 1986). This mobilization could involve changes in objective resources for managing stress, changes in cognitions (e.g., habituation, devaluation), or changes in coping strategies (Pearlin $\&$ Schooler, 1978). Pearlin et al. (1981) provided an example of one such 
process when they showed that chronic financial difficulty leads to the devaluation of monetary success and that this cognition, in turn, attenuates the association between acute financial stress and depression. In this fashion, the prior existence of a chronic difficulty can help facilitate a more benign appraisal of the subsequent acute stress and, in turn, reduce its emotional effect.

A third possibility has been suggested by Wheaton (1990), who argued that some acute life stresses may actually lead to the resolution of more chronic difficulties. An example is the resolution of ongoing marital difficulty (a chronic stress) by divorce (an acute stress). Indeed, both Wheaton (1990) and Aseltine and Kessler (1990) have presented panel data documenting that divorce is actually associated with a reduction in distress among respondents who previously reported seriously troubled marriages. Wheaton's analysis, furthermore, suggests that this kind of stress-reversal process may be a pervasive feature of many interpersonal stress situations.

An evaluation of these various possibilities requires more fine-grained measures and, in the ideal case, more dynamic data than we have here. All of the possibilities are plausible and consistent with the data. They differ, however, in their implications for theory and intervention. Given the scant attention paid to chronic stress in prior research and the even smaller emphasis on the possibility that chronic stress can modify the effects of acute stress, there is virtually no empirical basis for adjudicating among the different interpretations.

\section{Limitations of the Study}

This study has several significant limitations. The first is that the analysis is based on cross-sectional rather than longitudinal data. This makes it impossible to resolve the important issue of how much depression is an antecedent and how much a consequence of the stresses under consideration. This is a particularly important limitation for the comparative analysis of chronic and acute stress effects, because a plausible case could be made that selection effects are stronger for chronic than acute stresses. Differential selection could explain why the results reported here show the association between chronic stress and depressive symptoms to be stronger than the association between acute stress and depressive symptoms. It is more difficult to construct a post hoc interpretation of how selection could explain the negative interaction between chronic and acute stress.

Previous cross-sectional analyses of life events and depression have been able to provide some evidence on the selection issue by categorizing events along the dimension of independence from or dependence on prior mental health (e.g., see Brown \& Harris, 1989). Our comparative analysis of chronic 
and acute stress effects is limited by the fact that no such categorization is possible for the chronic stresses we consider because the chronicity of virtually all of them could be affected by prior mental health, even if the events that precipitated them were entirely independent. This problem has hampered efforts to investigate chronic stress effects with the same rigor as that applied to research on life events. A challenge for future investigation is to develop design and estimation options that help resolve this difficulty so that chronic stress effects can be compared with the effects of acute stress in a more unbiased fashion.

Our analysis documented the existence of important differences among disaggregated stresses. This finding highlights another limitation of the current study, that the sample is too small to provide statistically reliable estimates of stress effects at the most interesting level of disaggregation. Future investigations therefore require either much larger samples - which is not likely to be feasible in most cases-or designs that examine high-risk populations. The latter, particularly before-after investigations of people who have all been exposed to one particular kind of recent life event such as a job loss, widowhood, or life-threatening illness, would provide particularly rich opportunities to evaluate the modifying effects of prior chronic stresses and the processes that bring them about.

A final limitation is that our assessment of chronic stresses is probably much less comprehensive than our assessment of acute stresses. The measurement strategy used here is based on a life events approach. Virtually all major life events included in previous inventories have been included in our assessment. Chronic stresses, however, were only measured when they seemed to have analogs in acute stresses that we would recognize as important events. We included an assessment of ongoing marital difficulties, for example, to parallel the assessment of relations with spouse changing for the worse, which is found in most life event inventories. We did not, however, assess the feelings of inequality, unfulfillment, or emotional distance that might contribute to more subtle aspects of ongoing marital stress. As a result, it is likely that we underestimated the association between chronic stress and depression more so than the association between acute stress and depression.

\section{Conclusions}

The limitations described above preclude strong claims that our study demonstrates a more powerful effect of chronic than acute stress in causing depression or that chronic stress is a causally important modifier of acute stress effects. We can assert, however, that the associations documented here are consistent with the possibility that important chronic stress effects of this sort exist. Furthermore, these associations have been documented in a large 
and representative sample, using a strategy for assessing chronic and acute stresses that provides a representative characterization of major stresses in the proportions they are found in the population across a wide range of stress domains.

These results raise the possibility that previous research on stress, which has focused largely on acute life events, has been too narrowly conceived, and argues for a broadening of future research to consider the effects of chronic stress situations. This is by no means an easy thing to do. As pointed out above, it is much more difficult to make plausible interpretations of chronic stress effects than acute stress effects. Complex research designs, measurement strategies, and analysis schemes may have to be devised to allow a full investigation of chronic stress effects in the future (Kessler, 1987). In the absence of special efforts of this sort, it is possible that our research will ignore the most important types of stress for mental health.

\section{REFERENCES}

Abbey, A., Abramis, D. J., \& Caplan, R. D. (1985). Effects of different sources of social support and social conflict on emotional well-being. Basic and Applied Social Psychology, $6,111-129$.

Abramson, L. Y., Seligman, M. E. P., \& Teasdale, J. D. (1978). Learned helplessness in humans: Critique and reformulation. Journal of Abnormal Psychology, 87, 49-74.

Aseltine, R. H., Jr. \& Kessler, R. C. (1990). Marital disruption and depression: Evaluating the mediating and moderating effects of role context. Unpublished manuscript, Institute for Social Research, The University of Michigan, Ann Arbor.

Avison, W. R., \& Turner, R. J. (1988). Stressful life events and depressive symptoms: Disaggregating the effects of acute stressors and chronic strains. Journal of Health and Social Behavior. 29, 253-364.

Bolger, N., Delongis, A., Kessler, R. C., \& Schilling, E. A. (1989). Effects of daily stress on negative mood. Journal of Personality and Social Psychology, 57, 808-818.

Brown, G. W., \& Harris, T. O. (1978). Social origins of depression: A study of psychiatric disorder in women. New York: Free Press.

Brown, G. W. \& Harris, T. O. (1989). Life events and illness. New York: Guilford.

Caspi, A., Bolger, N., \& Eckenrode, J. (1987). Linking person and context in the daily stress process. Journal of Personality and Social Psychology, 52, 184-195.

Cleary, P. D., \& Kessler, R. C. (1982). The estimation and interpretation of modifier effects. Journal of Health and Social Behavior, 23, 159-169.

Cohen, J., \& Cohen, P. (1983). Applied multiple regression/correlational analysis for the behavioral sciences (2nd ed.). Hillsdale, $\mathrm{NJ}$ : Erlbaum.

Cohen, S., \& Wills, T. A. (1985). Social support: Stress and the buffering hypothesis. Psychological Bulletin, 98, 310-357.

Costello, C. G. (1982). Social factors associated with depression: A retrospective community study. Psychological Medicine, 12, 329-339.

Depue, R. A., \& Monroe, S. M. (1986). Conceptualization and measurement of human disorder in life stress research: The problem of chronic disturbance. Psychological Bulletin, 99, 36-51.

Derogatis, L. R. (1977). SCL-90: Administration, scoring, and procedures manual for the revised version. Baltimore, MD: Johns Hopkins University. 
Dohrenwend, B. P. (1979). Stressful life events and psychopathology: Some issues of theory and method. In J. F. Barrnett, R. M. Rose, \& G. L. Klerman (Eds.), Stress and mental disorder (pp. 1-15). New York: Raven.

Dohrenwend, B. S., Krasnoff, L., Askenasy, A. R., \& Dohrenwend, B. P. (1978). Exemplification of a method for scaling life events: The PERI life events scale. Journal of Health and Social Behavior, 19, 205-229.

Eckenrode, J. (1984). Impact of chronic and acute stressors on daily reports of mood. Journal of Personality and Social Psychology, 46, 907-918.

Elder, G. H. Jr. (1974). Children of the Great Depression: Social change in life experience. Chicago: Chicago Press.

Fiore, J., Becker, J., \& Coppel, D. B. (1983). Social network interactions: A buffer or a stress? American Journal of Community Psychology, 11,423-439.

Higgins, E. T., Rholes, W. S., \& Jones, C. R. (1977). Category accessibility and impression formation. Journal of Experimental and Social Psychology, 13, 141-154.

Holmes, T. H., \& Rahe, R. H. (1967). The social readjustment rating scale. Journal of Psychosomatic Research, 11, 189-194.

Horwitz, A. V. (1984). The economy and social pathology. Annual Review of Sociology, 10, 95-119.

Kessler, R. C. (1982). Life events, social support, and mental illness. In W. R. Gove (Ed.), Deviance and mental illness (pp. 247-271). Beverly Hills: Sage.

Kessler, R. C. (1987). The interplay of research design strategies and data analysis procedures in evaluating the effects of stress on health. In S. V. Kasl \& C. J. Cooper (Eds.), Stress and health: Issues in research methodology (pp. 113-140). New York: Wiley.

Kessler, R. C., \& Cleary, P. D. (1980). Social class and psychological distress. American Sociological Review, 45, 63-78.

Kessler, R. C., \& McLeod, J. D. (1984). Sex differences in vulnerability to undesirable life events. American Sociological Review, 49, 620-631.

Kessler, R. C., Turner, J. B., \& House, J. S. (1989). Unemployment, reemployment, and emotional functioning in a community sample. American Sociological Review, 54, 648-657.

Lazarus, R. S., \& DeLongis, A. (1983). Psychological stress and coping in aging. American Psychologist, 38, 245-254.

Lazarus, R. S., \& Folkman, S. (1984). Stress, appraisal, and coping. New York: Springer.

Marks, S. R. (1977). Multiple roles and role strain: Some notes on human energy, time, and commitment. American Sociological Review, 42, 921-936.

Mattlin, J. A., Wethington, E., \& Kessler, R. C. (1990). Situational determinants of coping and coping effectiveness. Journal of Health and Social Behavior, 31, 103-122.

McLeod, J. D., \& Kessler, R. C. (1990). Socioeconomic status differences in vulnerability to undesirable life events. Journal of Health and Social Behavior, 31, 162-172.

Mitchell, R. E., Cronkite, R. C., \& Moos, R. H. (1983). Stress, coping, and depression among married couples. Journal of Abnormal Psychology, 92, 433-448.

Neugebauer, R. (1981). The reliability of life events. In B. S. Dohrenwend \& B. P. Dohrenwend (Eds.), Stressful life events and their contexts (pp. 125-148). New Jersey: Rutgers University Press.

Pagel, M. D., Erdly, W. W., \& Becker, J. (1987). Social networks: We get by with (and in spite of a little help from our friends. Journal of Personality and Social Psychology, $53,793-804$.

Pearlin, L. I., Lieberman, M. A., Menaghan, E. G., \& Mullan, J. T. (1981). The stress process. Journal of Health and Social Behavior, 22, 337-356.

Pearlin, L. I., \& Schooler, C. (1978). The structure of coping. Journal of Health and Social Behavior, 19, 2-21.

Rahe, R. H. (1969). Life crisis and health change. In P. R. A. May \& J. R. Winterborn (Eds.), Psychotropic drug response: Advances in prediction. Springfield, IL: C C Thomas.

Riley, D., \& Eckenrode, J. (1986). Social ties: Subgroup differences in costs and benefits. Journal of Personality and Social Psychology, 51, 770-778.

Rook, K. S. (1984). The negative side of social interaction: Impact on psychological well-being. Journal of Personality and Social Psychology, 46, 1097-1108. 
Schuster, T. L., Kessler, R. C., \& Aseltine, R. H. (1990). Supportive interactions, negative interactions, and depressed mood. American Journal of Community Psychology, 18, 423-438.

Silver, R. L., \& Wortman, C. B. (1980). Coping with undesirable life events. In J. Garber \& M. E. P. Seligman (Eds.), Human helplessness: Theory and applications (pp. 279-375). New York: Academic Press.

Sudman, S., \& Bradburn, N. (1974). Response effects in surveys: A review and synthesis. Chicago: Aldine.

Thoits, P. A. (1983). Dimensions of life events that influence psychological distress: An evaluation and synthesis of the literature. In H. B. Kaplan (Ed.), Psychological stress: Trends in theory and research (pp. 33-103). New York: Academic Press.

Thoits, P. A. (1986). Multiple identities: Examining gender and marital status differences in distress. American Sociological Review, 51, 259-272.

Veroff, J., Douvan, E., \& Kulka, R. A. (1981). The inner American: A self-portrait from 1957 to 1976. New York: Basic Books.

Watson, D., \& Pennebaker, J. W. (1989). Health complaints, stress, and distress: Exploring the central role of negative affectivity. Psychological Review, 96, 234-254.

Wheaton, B. (1983). Stress, personal coping resources and psychiatric symptoms: An investigation of interactive models. Journal of Health and Social Behavior, 24, 208-229.

Wheaton, B. (1990). Life transitions, role histories, and mental health. American Sociological Review, 55, 209-223. 